\title{
Measurement of Labile Cu in Soil Using Stable Isotope Dilution and Isotope Ratio Analysis by ICP-MS
}

\author{
$\underline{\text { Annette L. Nolan }}^{1,2}$, Yibing Ma ${ }^{1}$, Enzo Lombi ${ }^{1}$, Mike J. McLaughlin ${ }^{1,3}$ \\ ${ }^{1}$ Centre for Environmental Contaminants Research, CSIRO Land and Water, PMB 2 Glen \\ Osmond, SA 5064, AUSTRALIA \\ ${ }^{2}$ Current address: National Measurement Institute, PO Box 385, Pymble, NSW 2073, \\ AUSTRALIA (annette.nolan@measurement.gov.au) \\ ${ }^{3}$ Soil and Land Systems, School of Earth and Environmental Sciences, The University of \\ Adelaide, PMB 1, Glen Osmond, SA 5064, AUSTRALIA
}

\section{INTRODUCTION}

Isotope dilution is a useful technique to measure the labile metal pool, which is the amount of metal in soil in rapid equilibrium with the soil solution. This is normally performed by equilibrating soil with a metal isotope, and sampling the labile metal pool using an extraction ( $E$ value), or by growing plants ( $L$ value). For $\mathrm{Cu}$, this procedure is problematic for $E$ values, and impossible for $L$ values, owing to the short half-life of the ${ }^{64} \mathrm{Cu}$ radioisotope (12.4 h), which makes access and handling very difficult. We therefore developed an $E$ value technique using enriched ${ }^{65} \mathrm{Cu}$ stable isotope and measurement of ${ }^{63} \mathrm{Cu} /{ }^{65} \mathrm{Cu}$ ratios by inductively-coupled plasma mass spectrometry (ICP-MS) to measure labile pools of $\mathrm{Cu}$ in soils [1]. The ${ }^{65} \mathrm{Cu} E$ values were compared to those determined using radioactive ${ }^{64} \mathrm{Cu}$.

\section{METHODS}

\section{$E$ values Determined Using Radioactive ${ }^{64} \mathrm{Cu}$}

Sub-samples ( $2 \mathrm{~g}$ ) of 12 soils were placed in centrifuge tubes to which was added $20 \mathrm{~mL}$ of water plus 2 drops of toluene in order to minimise microbial activity. The soil suspensions were equilibrated for $24 \mathrm{~h}$ in an end-over-end shaker. The samples were spiked with $50 \mu \mathrm{L}$ of solution containing ${ }^{64} \mathrm{Cu}\left(60 \mathrm{MBq} \mathrm{mL}{ }^{-1}\right)$ and returned to the shaker to equilibrate for $24 \mathrm{~h}$. At the end of the equilibration period the samples were centrifuged at $3000 \mathrm{~g}$ for $20 \mathrm{~min}$ and filtered through $0.2 \mu \mathrm{m}$ filters. Unlabelled $\mathrm{Cu}$ in the filtrates was measured using ICP-optical emission spectroscopy (ICP-OES, Spectro, SpectroFlame Modula). Activities of radioactive $\mathrm{Cu}$ in the filtrates were assessed using gamma spectrometry (1480 Wizard, Wallac). The labile $\mathrm{Cu}$ pool $(E)$ was determined using equation 1:

$$
E=\frac{C_{\text {sol }}}{C^{*}{ }_{\text {sol }}} \times R \times \frac{V}{W}
$$

where $\mathrm{C}_{\text {sol }}$ is the concentration of natural metal in solution $(\mu \mathrm{g} / \mathrm{mL}), \mathrm{C}^{*}$ sol is the concentration of radioisotope remaining in solution after equilibration $(\mathrm{Bq} / \mathrm{mL}), \mathrm{R}$ is the total concentration of radioisotope added to each sample $(\mathrm{Bq} / \mathrm{mL})$ and $\mathrm{V} / \mathrm{W}$ is the ratio of solution to soil sample.

\section{$E$ values Determined Using Stable ${ }^{65} \mathrm{Cu}$}

The technique described above for ${ }^{64} \mathrm{Cu}$ was used, with the following modifications. The soil suspensions were spiked with a small volume of solution containing enriched ${ }^{65} \mathrm{Cu}$ equivalent to either 0.25 or $4 \mathrm{mg} \mathrm{Cu}$ applied per $\mathrm{kg}$ soil. This was equivalent to approximately $1 \%$ of total $\mathrm{Cu}$ in soil. Copper isotope ratio $\left({ }^{63} \mathrm{Cu} /{ }^{65} \mathrm{Cu}\right)$ measurements were conducted using an Agilent 7500c ICP-MS (Agilent Technologies) without any collision cell gas. The labile $\mathrm{Cu}$ pool $(E)$ was determined using equation 2: 


$$
E=\mathrm{R} \times \frac{\mathrm{AW}\left(\mathrm{Cu}_{\text {nat }}\right)}{\mathrm{AW}\left({ }^{65} \mathrm{Cu}\right)} \times \frac{\mathrm{IR}_{\text {sp }}-\mathrm{IR}_{\text {meas }}}{\mathrm{IR}_{\text {meas }}-\mathrm{IR}_{\text {nat }}} \times\left(\mathrm{IR}_{\text {nat }}+1\right)
$$

where $\mathrm{R}$ is equal to the total concentration of ${ }^{65} \mathrm{Cu}$ in the spike (mg kg${ }^{-1}$ ), AW is atomic weight, $\mathrm{IR}_{\mathrm{sp}}$ is the $\mathrm{Cu}$ ratio in the ${ }^{65} \mathrm{Cu}$ spike solution, $\mathrm{IR}_{\text {meas }}$ is the measured $\mathrm{Cu}$ ratio in solution after spiking and $\mathrm{IR}_{\text {nat }}$ is the measured natural abundance $\mathrm{Cu}$ ratio.

\section{RESULTS AND DISCUSSION}

Mass spectral interferences in detection of ${ }^{63} \mathrm{Cu} /{ }^{65} \mathrm{Cu}$ ratios by ICP-MS in soil extracts were found to be minimal. Isotope ratios determined by quadrupole ICP-MS compared well to those determined by high-resolution (magnetic sector) ICP-MS. E values determined using the stable isotope technique compared well to those determined using the radioisotope for both uncontaminated and $\mathrm{Cu}$-contaminated soils (Fig. 1).

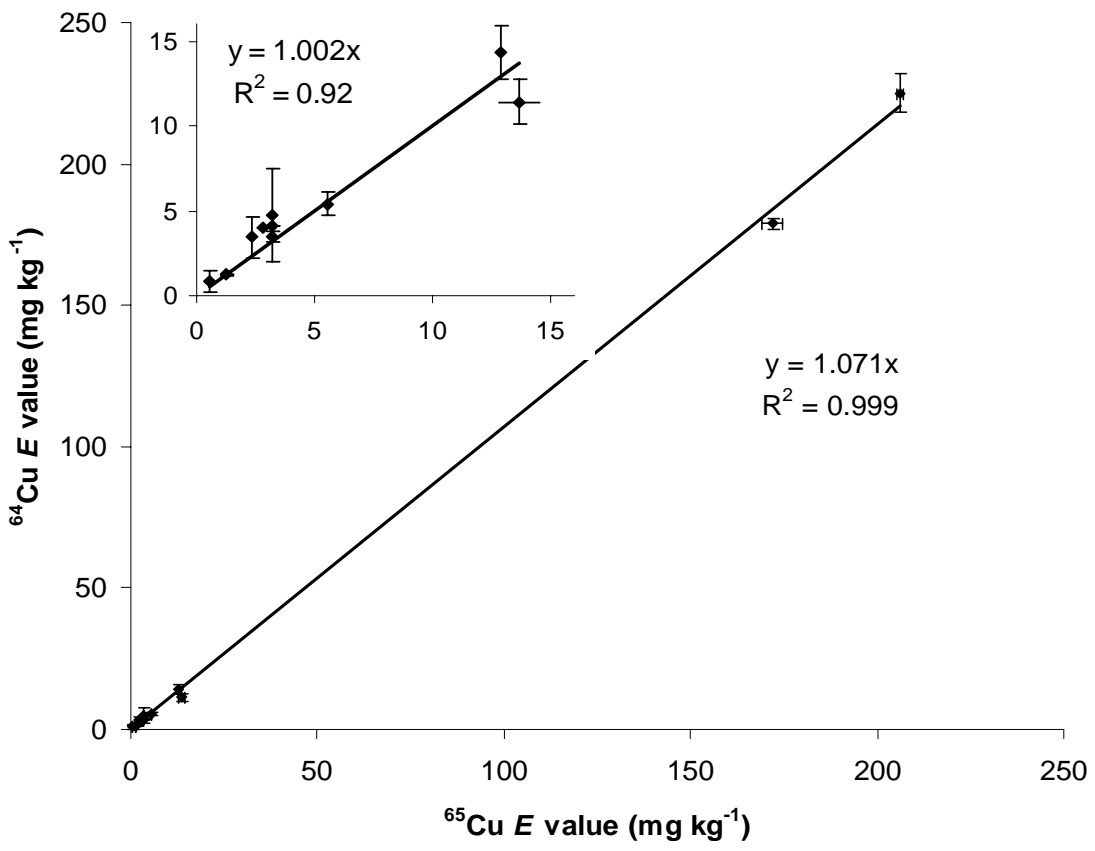

Fig. 1. ${ }^{65} \mathrm{Cu} E$ values versus ${ }^{64} \mathrm{Cu} E$ values for 12 soils.

\section{CONCLUSIONS}

This study shows that stable $\mathrm{Cu}$ isotope dilution can be used to determine the labile $\mathrm{Cu}$ pool in soils using isotope ratio measurements by quadrupole ICP-MS in the standard configuration. Good agreement was obtained between the measurements of labile $\mathrm{Cu}$ in soil using both stable and radioactive $\mathrm{Cu}$ isotope dilution, mutually confirming the two techniques. Isotope dilution techniques have been widely applied in the study of the fate and mobility of trace elements in soil, and the developed technique for $\mathrm{Cu}$ provides the potential for widespread application in trace element environmental soil research.

\section{ACKNOWLEDGEMENTS}

The authors thank the International Copper Association for supporting part of this work.

\section{REFERENCES}

[1] Nolan, A.L, Ma, Y., Lombi, E. and McLaughlin, M.J. (In press) Measurement of labile Cu in soil using stable isotope dilution and isotope ratio analysis by ICP-MS. Anal. Bioanal. Chem. 